\section{Digital tools for e-democracy}

\section{In brief}

- $\quad$ Digital tools make it possible for citizens to participate more easily in policy- and decisionmaking processes.

- Numerous local, national and European experiences with the use of digital tools can help improve decision-making processes.

- One of the most important factors for successful e-participation is a close and clear link to a concrete formal political process.

- The numerous international experiences with e-participation processes are also highly relevant for Austria.

\section{What is it about?}

E-democracy aims to promote democracy through the use of modern information and communication technology (ICT) and describes a broad scope of practices of public online engagement in political opinion-forming and decision-making. In the face of the long-standing and continuing democratic deficit of the European Union, e-democracy tools such as online petition portals or online consultation platforms present attractive options for increasing the democratic legitimacy of the EU by building bridges between European constituents and EU institutions. The communicative potential of the Internet and social media raises hopes of promoting a transnational European public sphere through political communication beyond existing borders.

The forms and functions of ICT use within e-democracy may vary greatly in terms of modes and functions of involvement, as can be seen from the following categorisation of e-democracy tools.
Monitoring tools serve to monitor, question and advise policy-makers, e.g. parliamentary monitoring websites. Agenda-setting tools can be formal or informal, e.g. petition, consultation or crowdsourcing websites and citizen initiatives. Decision-making tools can be binding (e.g. e-voting) or non-binding (e.g. various e-budgeting processes)

Success is largely determined by the design and implementation of these tools. In the underlying study, suggestions for the improvement of already existing instruments were formulated and new possibilities explored.

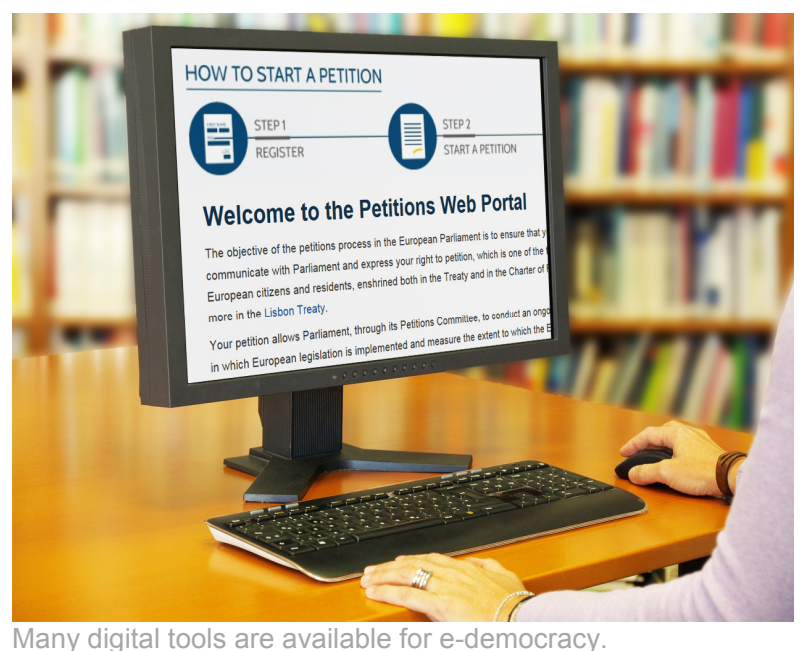

Despite initial high expectations, the lack of political or policy impact has proven to be an ongoing shortcoming of e-democracy projects, with success often pertaining to community-building and perceptions of personal growth. In cases of poor execution, e-participation may even lead to the opposite of the desired effect, resulting in disillusionment and increased distrust of the EU. A lack of transparency is one of the causes of such undesirable consequences.

In general, EU policy-makers and the public appear to have a large interest in e-participation. In part, this is due to many citizens' having the desire to gain more political say in the EU. The question arises how the large potential of e-democratic tools can be harnessed in order to benefit both policy-makers and the public (citizens and civil society organisations), and therefore democracy itself.

\section{Basic data}

Project title: EDEM: Digital tools for

Project team: G. Aichholzer, G. Rose (in an international consortium)

Duration: 06/2016 - 02/2017

Funded by: $\quad$ European Parliament - STOA Science and Technology Options Assessment 


\section{Key results}

Introducing new e-participation processes and improving already established ones can lead to citizens enjoying greater influence on agenda-setting and decision-making.

A close and clear link between e-participation processes and a concrete formal policy or political process proved to be one of the most important factors for ensuring successful e-participation. Many non-binding forms of e-participation do not automatically guarantee political uptake of citizens' input, in particular when these contributions are very broad and general in nature, making them difficult to implement.

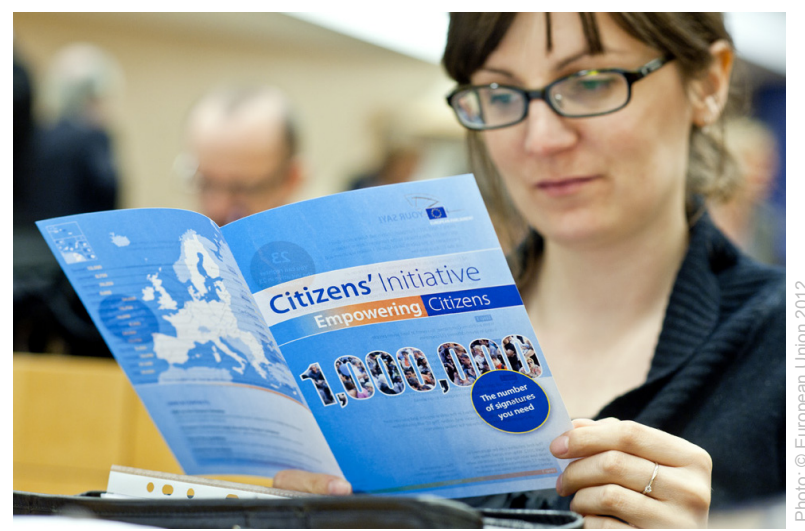

So far, the European Citizens' Initiative (ECI) has had limited concrete policy achievements.

Participant satisfaction is strongly related to the transparency of the participatory process. Disappointment can be avoided if it is clear from the onset what expectations one may have regarding the impact of ones' contributions on the decision-making process. Feedback on how results were ultimately taken into consideration strengthens confidence in the system.

Moreover, the participatory process should not be limited to one event but be embedded in an institutional "culture of participation". It must be possible to gain experience and to incorporate user feedback for digital participation tools to be continuously improved and expanded.

In order to be effective, e-participation must be accompanied by an effective mobilisation and engagement strategy, involving communication instruments tailored to different target groups. Offline communication strategies are central to achieving broad participation.

\section{What to do?}

The numerous international experiences acquired with e-participation are also of great relevance for Austria.

- At national level it is appropriate for digital tools to facilitate exchange among participants. Moreover, the possibility to interact with decision-makers would greatly increase the influence of citizens.

- Visualisation aids such as infographics or "traffic light systems" can be used to increase the transparency of participatory processes. Feedback regarding which contributions were included should be provided.

- Developing a media strategy at the beginning of a new process can help reach a large amount of citizens. Endeavours to mobilise citizens can be strengthened through the involvement of partners such as civil society organisations.

- Investments must be made to remove system vulnerabilities in e-voting before commencing with widespread implementation.

\section{Further reading}

Korthagen, I.; van Keulen, I.; Hennen, L.; Aichholzer, G.; Rose G., Lindner, R.; Goos, K.; Øjvind Nielsen R. (2018) Prospects for e-democracy in Europe.

European Parliament - STOA Science and

Technology Options Assessment

europarl.europa.eu/RegData/etudes/STUD/ 2018/603213/EPRS STU(2018)603213 EN.pdf

\section{Contact}

\section{Gloria Rose}

Email: tamail@oeaw.ac.at

Phone: +43(1)51581-6582

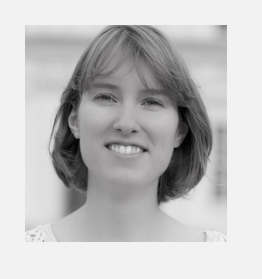

